Revista de Dialectología y Tradiciones Populares, vol. LXXII, n. ${ }^{\circ}$ 1, pp. 29-36, enero-junio 2017 , ISSN: 0034-7981, eISSN: 1988-8457, doi: $10.3989 /$ rdtp.2017.01.001.03

\title{
Comiendo fuet en Londres: de la autoetnografía a la etnografía transnacional
}

\author{
Eating fuet in London: From Autoethnography \\ to Transnational Ethnography
}

\author{
Clara Rubio ${ }^{1}$ \\ Universitat de Lleida
}

\section{RESUMEN}

La propia experiencia como joven española emigrada a Londres me llevó a valorar la importancia que la comida española ejerce entre los jóvenes emigrantes y a preguntarme qué papel juega en su proceso migratorio. De este modo, el presente artículo presenta la comida como metáfora del proceso de migración de los jóvenes españoles en Londres durante el periodo de crisis económica que empezó en 2008, basando el análisis en tres elementos: la construcción de su identidad, la transición que hacen hacia la vida adulta y su condición de transmigrantes.

Palabras clave: Autoetnografía; Juventud; Migración; Londres; Comida; Identidad.

\section{SUMMARY}

My own experience as a young Spanish migrant in London drove me to consider the importance that Spanish food has for emigrants and to consider its role within the community. This article presents food as a metaphor of the youth migration process to London during the economic crisis, and is based on three elements: how they construct their identity, their transition to adulthood and their condition as transmigrants.

Key words: Autoethnography; Youth; Migration; London; Food; Identity.

\footnotetext{
${ }^{1}$ Correo electrónico: clara.ruro@gmail.com. ORCID ID: http://orcid.org/0000-0001-5892-5805.
} 


\section{INTRODUCCIÓN}

Veo que mereció la pena ir cargada con $20 \mathrm{~kg}$ : lámpara, jarra de agua, $1 / 2 \mathrm{~kg}$ de fuet... ¡Pareces una exploradora! (fragmento de un correo que me envió mi madre el día 15 de enero de 2012 durante mi primera estancia en Londres).

Este artículo trata el tema de la emigración juvenil española a Londres durante el periodo de crisis económica iniciado en 2008. Yo misma fui una de estas jóvenes que se fue durante la crisis, aunque mi proceso migratorio no fue debido a la situación económica del país. Mi primer contacto con Londres fue como estudiante Erasmus a la University College of London del cual regresé feliz por la experiencia pero sin ningún interés por alargarla. Como mínimo, hasta que unos meses después visité a una amiga a Londres y conocí un muy buen motivo para irme a vivir allí otra vez: mi marido. Así que volví a vivir a la capital británica durante tres años más, hasta que regresé definitivamente a Barcelona a finales del año 2015. Fue durante esta segunda estancia que desarrollé el trabajo de campo para la tesis doctoral sobre la emigración juvenil, en el cual se basa el presente artículo.

El hecho de formar parte del colectivo estudiado es un reto, ya que pone en cuestión el papel del propio investigador: ¿la muestra escogida ha estado condicionada por su experiencia en el campo?, ¿la interpretación que hace de los hechos está condicionada por lo que ha vivido?, etc. Y es realmente un reto, pero el hecho de compartir con los informantes experiencias vividas también ayuda a formular preguntas de investigación que tal vez sólo aparezcan gracias a haber tenido la experiencia en primera persona.

Uno de los temas que más me interesó durante el trabajo de campo fue el papel que ejerce la comida entre los jóvenes españoles que han emigrado a Londres. El fragmento del correo electrónico que me envió mi madre y que abre el artículo fue enviado unos días después de haber vuelto a Londres tras mis vacaciones de Navidad en el año 2012. La estancia en Barcelona me permitió cargar con cosas que necesitaba y/o echaba de menos de mi hogar. Como se ve, había cosas prácticas como una jarra para filtrar el agua, una lámpara de mesa, ropa... pero en esa maleta de $20 \mathrm{~kg}$ que transportaba elementos de valor también había una cosa que echaba mucho de menos en Londres: el fuet ${ }^{2}$. De hecho, ese día marcó un antes y un después de mi estancia en la capital británica. Desde ese primer viaje, cada vez que iba a Barcelona o que alguien venía a visitarme a Londres pedía que me trajeran fuet o jamón, o los dos; y poco a poco esta lista se fue ampliando hasta el punto de haber llevado fiambreras con comida preparada de mis padres o con un trozo de mona de Pascua ${ }^{3}$ que había sobrado de la celebración. Poco a poco esta costumbre se convirtió en normativa hasta el punto de que las últimas horas de cada una de mis estancias en Barcelona las pasaba en la charcutería del barrio comprando paquetes envasados individuales de jamón y fuet (claro está, así duraban más) para podérmelos llevar a Londres.

En un primer momento no me percaté de la importancia que tenía la comida en mi vida cotidiana londinense, pero poco a poco empecé a notar que los jóvenes ca-

\footnotetext{
${ }^{2}$ Definición RAE: embutido estrecho y largo, parecido al salchichón, típico de Cataluña.

${ }^{3}$ Definición Enciclopedia Catalana: coca o pastel generalmente decorado con un huevo duro que se come por la fiesta de Pascua.
} 
talanes y españoles que me rodeaban tenían un interés similar al mío en conseguir productos españoles, llegando incluso al "tráfico" de alimentos; por ejemplo, el caso de gente que volvía a España tras su estancia en Londres y que vendía o regalaba productos españoles que no había llegado a consumir. Fue entonces cuando me pregunté: ¿qué papel ejerce la comida y la alimentación entre los jóvenes catalanes y españoles en Londres? Así pues, en este artículo me dispongo a apuntar algunas ideas que tras mi experiencia como joven emigrada a Londres y como antropóloga que ha hecho trabajo de campo ${ }^{4}$ he podido desarrollar, usando la comida como metáfora del proceso de emigración juvenil española para mostrar su importancia en tres sentidos: la identidad de estos jóvenes, la transición que hacen hacia la vida adulta y su condición de transmigrantes.

\section{COMIDA: IDENTIDAD Y NOSTALGIA}

Uno de los primeros "shocks" culturales que los españoles tienen cuando llegan a Londres está relacionado, precisamente, con la comida. Los españoles que llevan poco tiempo en la ciudad británica sólo son capaces de detectar, en general, el Fish and Chips y el English Breakfast como platos típicos del país. Es el caso del próximo joven, que decide comerse un típico plato de Fish and Chips como manera para empezar a integrarse a Londres.

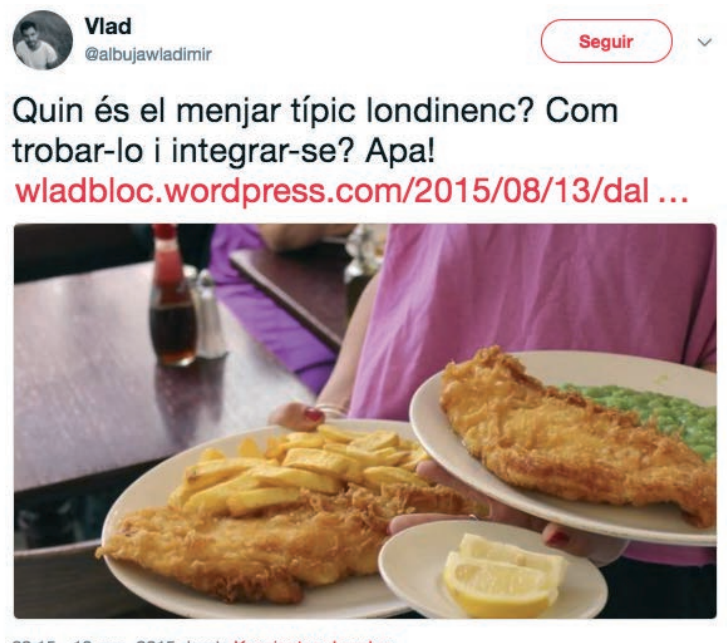

22:15 - 13 ago. 2015 desde Kensington, London

IMAGEN 1.-Tweet del 13 de agosto de 2015 encontrado usando un buscador online, dice: “¿Cuál es el plato típico londinense? ¿Cómo encontrarlo e integrarse? Ale!».

${ }^{4}$ El trabajo de campo se ha llevado a cabo entre los años 2013 y 2015 en la ciudad de Londres desarrollando 42 entrevistas en profundidad a jóvenes catalanes de diferentes perfiles (variables: edad, sexo, motivaciones para ir a Londres, niveles educativos y tipología de trabajo en Londres), observación participante, grupos de discusión y seguimiento de dos grupos en Facebook: Catalans a Londres y Españoles en Londres. 


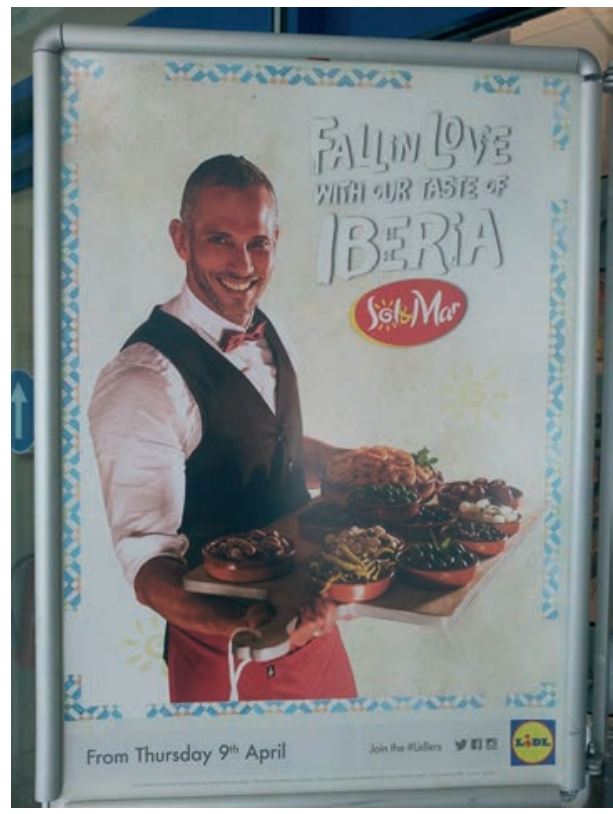

IMAGEN 2.-Anuncio en el supermercado Lidl, abril de 2015, recogido durante el trabajo de campo.
Es también durante estos primeros momentos de su estancia en la ciudad, sobre todo el primer año, que los jóvenes españoles usan la comida española como manera de acercarse a los orígenes que sienten lejanos debido a su proceso migratorio: su familia, sus amigos, su cultura; sobre todo en fiestas señaladas como Navidad o Pascua, momentos en que la nostalgia aparece con más fuerza. La comida, pues, se convierte en una reafirmación de su identidad y una manera de lindar con la añoranza, como en el caso de la siguiente joven:

¡Hola! Como estamos en pascuas, y echo de menos algo español, y me acuerdo de mi madre y sus torrijas, quería preguntaros si las habéis hecho y con qué pan, si podéis poner aquí vuestra receta, me gustaría hacerla [emoticono de corazón]. También ella puso una foto en su Facebook de unos churros con chocolate y me dio morriña, sé que en Camden los venden súper ricos en la calle, en el mercado a unas 4 libras. Sabéis si venden en algún lugar churros congelados? No sé por qué pero tengo morriña hoy. Un saludo a todos y felices pascuas.

(Comentario en Facebook, grupo "Españoles en Londres", 20 de abril de 2014).

Algunas compañías de supermercado han aprovechado este sentimiento de nostalgia para hacer negocio con él. Es el caso, entre otros, de Lidl, que ha hecho diferentes campañas de productos españoles en Londres. Ésta, en concreto, se llamaba Fall in love with our taste of Iberia (enamórate del sabor ibérico), y el cartel muestra un joven latino sonriente sirviendo una tabla de madera con diferentes tapas, dos de los clichés de España entre los británicos: la buena comida y la gente feliz. Aunque se trata de una campaña destinada al público británico, suscitó gran interés entre la comunidad española por ser la primera que se dio de manera mayoritaria en la ciudad y que acercaba, a precio asequible, productos españoles a la capital británica.

Otros negocios étnicos informales han aparecido, como por ejemplo negocios de personas individuales que cocinan en casa y venden la comida a otros españoles en Londres. Es el caso de este chico:

Hola chavales, por si os interesa y os entra morriña de una buena tortilla de patatas para llevar a casa por un módico precio contactarme por privado. Gracias, que tengáis un buen día (comentario en Facebook, grupo "Españoles en Londres", 16 de agosto de 2015).

\section{SOBRE COCINAR (O CÓMO HACERSE MAYOR)}

Es común encontrar fotos en las redes sociales de jóvenes españoles que han cocinado platos típicos españoles durante su estancia en Londres y los quieren compar- 
tir con el resto de la comunidad: tortillas de patatas, lentejas, croquetas... siendo esta una manera de lidiar con la nostalgia que sienten.

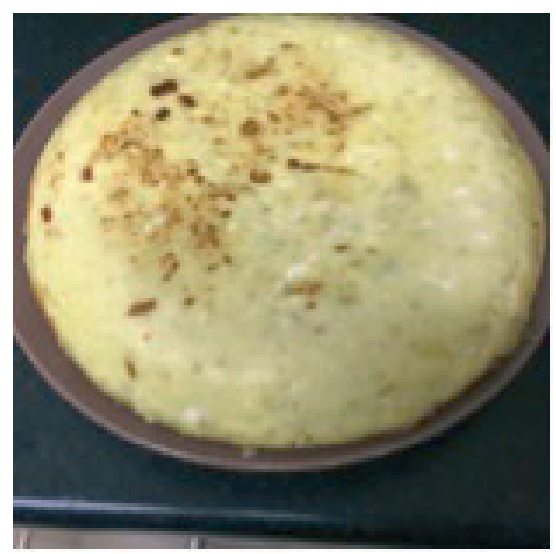

IMAGEN 3.-Fotografía colgada en Facebook en el grupo "Españoles en Londres" con el comentario: «Post no serio! ¡Primera tortilla londinense! ¡Mira qué arte!» (4 de octubre de 2015).

Para muchos de ellos es la primera vez que intentan cocinar estos platos ya que es la primera vez que tienen la necesidad de hacerlo. El proceso migratorio les ha supuesto una emancipación domiciliar y, en consecuencia, una necesidad de desarrollar las tareas domésticas asociadas. Así pues, para muchos de ellos es la primera vez que deben cocinar, lavar, comprar... siendo esta una experiencia totalmente nueva. Es a partir de este ejemplo que también podemos analizar la emigración juvenil española como una estrategia para llevar a cabo la transición a la vida adulta. En algunos casos, como el que se muestra a continuación, la emigración a Londres fue concebida como una estrategia para poder emanciparse de casa de sus padres. No veían posible independizarse en España debido a que las pocas y precarias ofertas laborales no les garantizaba poder pagar las facturas cada mes, así que usaron la emigración a Londres como una estrategia para poder tener un espacio propio con su pareja:

Yo aquí [Londres] vivo sola con mi pareja, tengo un buen trabajo, aburrido y mecánico pero bueno, y cuando vuelva allá [Barcelona] los primeros días, las primeras impresiones serán: que no tendré novio porque estará en su casa, que yo estaré en la mía, con mi madre súper protectora tocándome las narices, sin trabajo, sin hacer nada y con pocos ahorros (Clàudia. Entrevista en profundidad, 14 de enero de 2013).

\section{LA COMIDA: PUENTE ENTRE DOS CULTURAS}

Es recurrente encontrar, en las redes sociales de las comunidades españolas y catalanas analizadas, personas que preguntan cuál es la mejor opción de envío internacional entre España y el Reino Unido. En algunos casos esta pregunta va destinada a enviar maletas para el traslado hacia uno de los dos países, pero en muchos otros se busca la mejor opción para que la familia les pueda enviar cajas llenas de comida a 
Londres. Este es el caso de Sandra, una joven chica que enseña con mucho orgullo una foto en la que se muestra una caja llena de chorizo, jamón, butifarra, galletas, vino e incluso una jarra de filtrar agua que su familia le ha enviado.

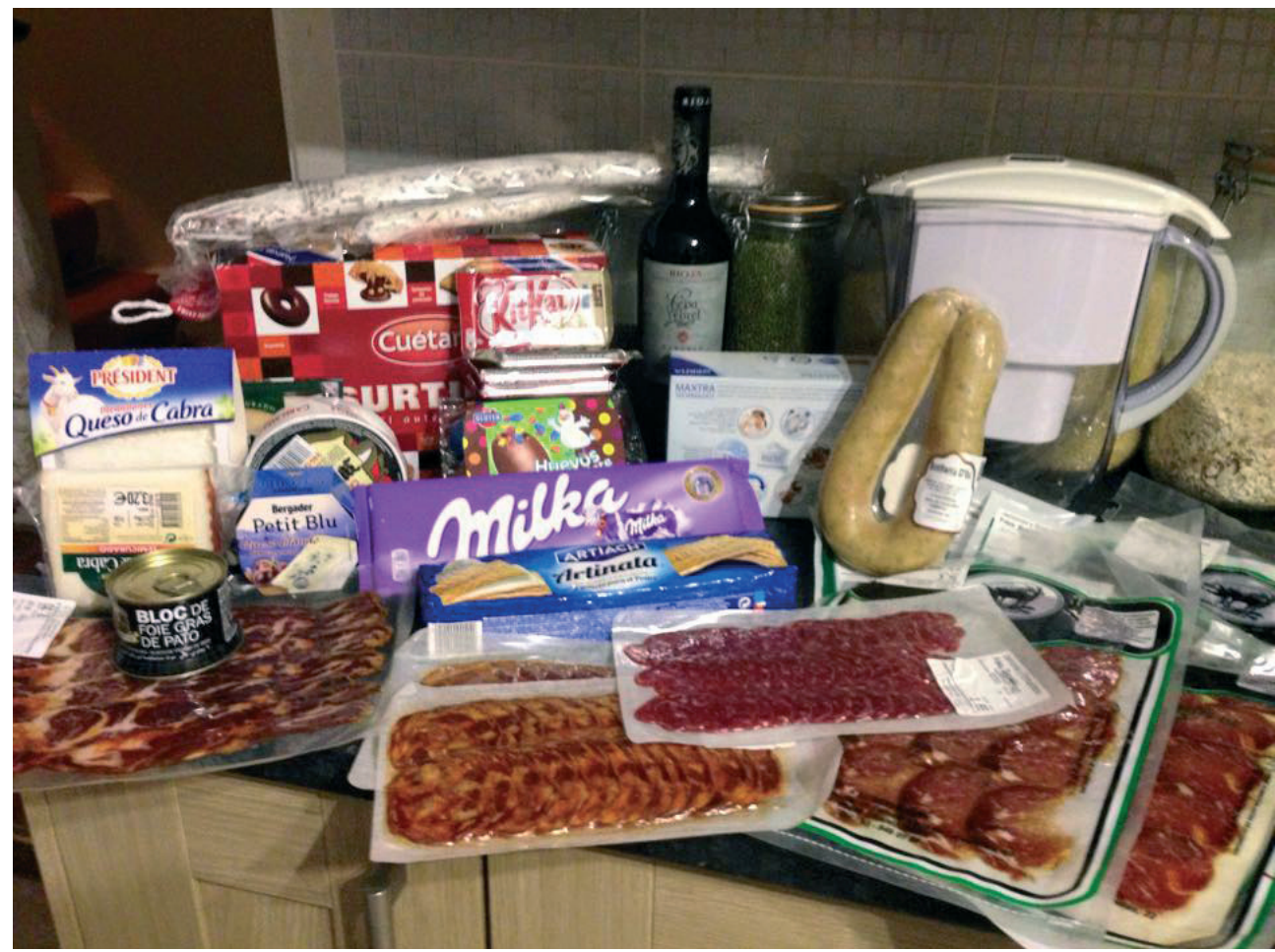

IMAGEN 4.-Fotografía de una joven española en Londres que muestra el último envío de comida que su familia le ha hecho, en el grupo de Facebook "Catalans a Londres".

También es común que aquellos más nuevos en la ciudad pregunten si es legal traer comida cocinada en la maleta de mano en su viaje de regreso a Londres. Algunos de ellos, que suponen que pueden llevar consigo comida comprada en supermercados ya que cumplen con los requisitos de la Unión Europea, no lo tienen tan claro sobre comida preparada por sus madres o abuelas y que quieren llevar en una fiambrera. La respuesta que se da siempre es positiva, diciendo que ellos mismos ya lo han hecho antes y no les ha pasado nada.

Paralelamente, se ha observado una gran cantidad de personas que preguntan por restaurantes españoles en Londres de buena calidad. Muchos de ellos argumentan que quieren llevar a sus amigos británicos o internacionales a probar una buena paella española o a comer tapas, por este motivo necesitan que sea lo más "auténtico" posible. Como hemos visto anteriormente, la comida es muy relevante en la construcción y reafirmación de su identidad como españoles, por ese motivo es muy importante 
para ellos poder mostrar sus orígenes a sus nuevos amigos internacionales de la manera más fidedigna posible.

Buenas! Tengo una preguntilla a ver si alguien me puede ayudar, este fin de semana celebro mi cumpleaños y quiero llevar a mis colegas a un restaurante español donde hagan buenas paellas. Todos ellos son ingleses pero me molaría que probaran una buena paella, no algo congelado o con chorizo (que seguro que están buenas pero...). Estoy buscando uno que esté céntrico puesto que luego nos queremos ir a algún pub. Muchas gracias (comentario en Facebook, grupo "Españoles en Londres”. 28 de agosto de 2015).

Así pues, por un lado, el envío de comida española permite a los jóvenes mantener sus redes sociales de origen, sobre todo la red familiar, a la vez que la propia comida les permite también conectar con su cultura de origen cada vez que la consumen. Por otro lado, la comida española también les permite establecer nuevos contactos en Londres; estos jóvenes están forjando nuevas amistades internacionales y británicas durante su estancia y usan la cocina española (famosa por la paella, las tapas y la sangría) para mostrarles un poco más de ellos mismos y de dónde proceden. Es en este sentido que la comida puede ser también un ejemplo de su condición de transnacionales: son jóvenes emigrados que continúan manteniendo sus redes de contacto en origen a la vez que construyen las nuevas en destino.

\section{APUNTES FINALES}

A partir de considerar la comida como metáfora del proceso emigratorio de los jóvenes españoles en Londres hemos podido analizar tres elementos claves del proceso: la nostalgia hacia sus orígenes, ligada a su identidad; la emancipación domiciliar y la consecuente transición a la vida adulta; y su condición de transmigrantes.

"Comer es digerir culturalmente el territorio" (Delgado 2001) y, de hecho, eso es lo que hacen los jóvenes españoles que viven en Londres: usan la comida española para reafirmar su identidad y, con cada bocado que toman, mantenerse más cerca de donde vienen. Del mismo modo, la experiencia de tener que cocinar recetas españolas - que pocas veces habían cocinado antes - se relaciona con un elemento importante de la emigración de los jóvenes españoles: para muchos de ellos la emigración supone ser la primera vez que viven independizados y, por consiguiente, la primera vez que se emancipan de sus padres y que deben hacer ellos mismos las tareas domésticas. Así pues, vivir en Londres supone para ellos una experiencia internacional con gran importancia a nivel personal. Finalmente, es también la comida la que nos ha ayudado a dibujar su condición de transmigrantes: mantienen sus redes de origen a través de envíos de comida del mismo modo que usan la comida española para mostrar un poco más de sí mismos a sus nuevas amistades internacionales en Londres.

La comida, pues, nos acerca a ver cómo es la vida de estos jóvenes españoles en Londres y a la vez abre otros frentes de debate: ¿mantienen para siempre esta condición de transmigrantes con la comida, hasta cuándo la familia les envía comida?, o qué pasa con los jóvenes que han pasado una temporada larga en Londres, ¿̇hacen el mismo proceso a la inversa en su retorno a España? 


\section{BIBLIOGRAFÍA CITADA}

Delgado, Ramiro. 2001. "Comida y cultura: identidad y significado en el mundo contemporáneo". Estudios de Asia y África 26(1): 83-108. 